\title{
REINTEGRA - PLATAFORMA PARA AUXÍLIO À REINTEGRAÇÃO DE EGRESSOS DO SISTEMA PRISIONAL BRASILEIRO AO MERCADO DE TRABALHO FORMAL
}

\author{
Lucas de Freitas Kauer, Rodrigo Remor Oliveira, Raquel Salcedo Gomes
}

Instituto Federal do Rio Grande do Sul - IFSUL - Campus Sapucaia do Sul

CEP: 93.216-120 - Sapucaia do Sul - Rio Grande do Sul - Brasil

(lucas.kauerrs@hotmail.com, remoreifsul.edu.br, raquelsalgo@gmail.com)

\begin{abstract}
Resumo. A pesquisa tem como objetivo desenvolver uma plataforma digital que visa a minimizar as principais dificuldades que egressos do sistema prisional encontram ao tentar se reinserir no mercado de trabalho formal e no âmbito acadêmico. A população carcerária brasileira carece de atenção no cunho político-social. Devido a isso, o trabalho tem como tema a relação entre a computação digital e a reintegração social de egressos de penitenciárias brasileiras. Com esse contexto, busca-se identificar maneiras de minimizar a cobrança de experiência para a reinserção de egressos ao mercado de trabalho formal. O referencial teórico apoia-se na filosofia foucaultiana e em pesquisas relacionadas ao tema das áreas de sociologia, psicologia e serviço social. A metodologia, de cunho quali-quantitativo, foi desenvolvida especialmente para esta investigação, compondo-se de oito etapas, iterativamente avaliadas. Os instrumentos utilizados foram caderno de campo digital, questionários e entrevistas. A partir das respostas da primeira entrevista, concluiu-se que não há um preparo ou uma reeducação social dentro dos presídios ou após o egresso. Com isso, surge uma dificuldade tanto para o regresso ao mercado de trabalho quanto para a sociedade em si. A plataforma é dividida em uma arquitetura de cliente-servidor, a fim de aumentar a interoperabilidade do sistema. Como considerações finais, constata-se a relevância do projeto de desenvolvimento tecnológico, tendo em vista a carência de projetos relacionados com a proposta aqui apresentada. Ademais, o preconceito, a falta de políticas públicas e de contingências legais dificultam a reintegração de egressos, o que se pretende mitigar com o desenvolvimento desta plataforma.
\end{abstract}

\section{Introdução}

A população carcerária é, em grande parte, composta por indivíduos à mercê da sociedade, pessoas que foram isoladas do convívio social antes mesmo de serem afastadas pelo aprisionamento (MISSE, 2006, p. 23). Devido a isso, a reintegração dos socialmente excluídos, daqueles que tiveram pouca ou nenhuma oportunidade durante todo o seu percurso de subsistência, é árdua. Os termos reintegração e ressocialização possuem significados distintos. Reintegrar um apenado é investir novamente nele, tencionando o restabelecimento dos valores sociais do coletivo (OLIVEIRA, 1972). Em contrapartida, ressocializar um indivíduo remete a modificar seu comportamento, de modo a torná-lo congruente com o comportamento socialmente aceito e não nocivo à sociedade (DOTTI, 1998). A negligência do governo para com a população carcerária no Brasil é ainda 
rejeitada ou discriminada por parte da sociedade. A responsabilidade de ressocializar o apenado é do Estado (GRECO, 2011, p. 477), de modo que se pode pensar em alternativas para aprimorar o atual modelo de punição penal. Esta pesquisa visa a elucidar os problemas enfrentados por egressos do sistema prisional brasileiro ao mercado de trabalho formal, entender seus mecanismos de funcionamento para, de maneira pragmática, oferecer uma alternativa para aprimorar a efetividade dos artigos legais que protegem os direitos dos egressos do sistema prisional.

\section{Trabalhos Relacionados}

Com a finalidade de identificar os projetos já existentes nesta área e compreender o cenário com o qual essa investigação se compromete, foi realizada uma pesquisa em lojas de aplicativos digitais no dia 19 de julho de 2017. Entretanto, não foram encontrados trabalhos que compartilham do objetivo desta pesquisa. Buscando outros meios, foram encontrados projetos sociais relacionados à governos estaduais brasileiros, que possuem um propósito semelhante. Entre eles está o Começar de Novo, programa realizado pelo CNJ, com o slogan "quem já pagou pelo que fez tem a chance de começar de novo". O programa visa a sensibilizar a sociedade a respeito da reintegração deste público, ressaltando a importância de sua capacitação, para estarem aptos a desempenhar seus ofícios, e das empresas aceitarem egressos do sistema prisional para ingressarem no seu quadro de funcionários. Através do Portal de Oportunidades, empresas (públicas ou privadas) e cidadãos conseguem atualizar tanto vagas de empregos quanto cursos profissionalizantes. Deste modo, convém ao egresso estar cadastrado no programa e estar atento às atualizações. Empresas que colaboram com o programa ganham o Selo do Programa Começar de Novo ${ }^{1}$.

\section{Metodologia}

\subsection{Pesquisa Exploratória}

A fim de obter dados e melhor identificar as necessidades do público-alvo, foi realizada uma pesquisa exploratória (CERVO; BERVIAN; SILVA, 2007, p.61), voltada a egressos de penitenciárias brasileiras. Para tal, foi realizada uma entrevista de modo presencial no Mercado Público de Porto Alegre/RS com uma pessoa que já fez parte da população carcerária brasileira. Tal método permitiu o conhecimento do processo de reinserção das pessoas com comportamentos desviantes, desde a entrada na prisão até sua saída dela, e também o funcionamento na prática do sistema carcerário brasileiro. A partir das respostas do entrevistado, conclui-se que não há um preparo, uma reeducação social, dentro dos presídios. Com isso, surge uma dificuldade tanto para o regresso ao mercado de trabalho quanto para a sociedade em si, incluindo sua família, afinal, o suporte familiar passa a ser peça fundamental para a ressocialização do egresso, já que passa a haver um distanciamento das responsabilidades por parte do Estado para com esses indivíduos.

\footnotetext{
1 CONSElHO NACIONAL DE JUSTIÇA. Começar de Novo. 2010. Disponível em $<$ http://www.cnj.jus.br/sistema-carcerario-e-execucao-penal/pj-comecar-de-novo $>$. Acesso em 26 de julho de 2017.
} 


\subsection{Desenvolvimento e Tecnologias}

Para suprir as necessidades do público-alvo, foi realizado o desenvolvimento de um software $^{2}$ com as seguintes funcionalidades: às empresas homologadas cadastrar ofertas de vagas de emprego e cursos de qualificação profissional, bem como visualizar as informações dos egressos que se candidatarem às vagas de emprego ou aos cursos ofertados. Além disso, as empresas podem solicitar o histórico e a evolução dos egressos nos cursos e treinamentos em que se fizeram presentes. Os boletins relacionados tanto às Organizações Governamentais e Organizações Não Governamentais quanto as leis e informações legais encontram-se em estágio de aprimoramento, enquanto que a divulgação de publicidade não foi implementada. Os egressos podem divulgar os seus perfis profissionais e visualizar vagas de emprego ofertadas. Algumas funcionalidades, podendo-se citar a candidatura às vagas de emprego e cursos de capacitação profissional, encontram-se em estágio de desenvolvimento. Acredita-se que essas funcionalidades são de extrema importância para a capacitação de egressos e aumentam a probabilidade de ingresso no mercado de trabalho formal.

A plataforma é composta de três componentes chamados de reintegra-server ${ }^{3}$, reintegraclient $^{4}$ e reintegra-app, que utilizam de tecnologias específicas e possuem responsabilidades distintas. O reintegra-server é a aplicação responsável por manusear os dados, persistindo, entregando, atualizando e deletando informações através do sistema de mensagens. Já o reintegra-client e reintegra-app são as interfaces do usuário, onde boa parte da responsabilidade foi empregada.

O componente reintegra-server, desenvolvido na linguagem de programação JavaScript, utilizando a plataforma de desenvolvimento Node.js (MOREIRA, 2013), é responsável por disponibilizar recursos, sob forma de serviços. A arquitetura empregada para a construção do servidor é chamada de REST, sua escolha se deve ao fato dela oferecer todo a diretriz necessária para a construção de serviços coesos, escaláveis e performáticos. Outra vantagem da arquitetura de escolha quando comparada à clássica arquitetura monolítica, é sua melhor escalabilidade e manutenibilidade.

A ascensão das Single Page Applications (SPA) se deve ao fato de que no desenvolvimento tradicional o tempo para atender a uma requisição é muito alto. Isto posto, a biblioteca ReactJS, desenvolvida pelas equipes do Facebook e Instagram e comunidade, foi estabelecida para a construção das interfaces. Há vários frameworks e bibliotecas frontend feitas em JavaScript (podendo-se citar jQuery, AngularJS, Angular, $V u e . j s$ e o próprio ReactJS) e a escolha pelo ReactJS se deve ao fato dele resolver, de forma simples e otimizada, o problema da renderização de componentes. Entende-se por componentes as partes independentes e reutilizáveis da interface, são eles que detêm a lógica tanto para lidar com a sua exibição quanto para a exibição em si. Algumas telas do aplicativo são demonstradas na Figura 1.

\footnotetext{
2 Todo programa de computador e sua documentação associada (SOMMERVILLE, 2007).

${ }^{3}$ Repositório no GitHub https://github.com/lucaskauer/reintegra-server

${ }^{4}$ Repositório no GitHub https://github.com/lucaskauer/reintegra-client
} 


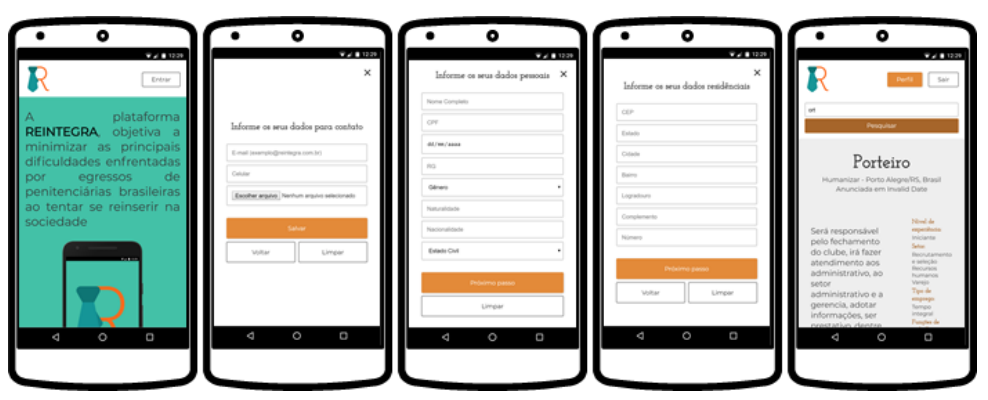

Figura 1. Telas do Sistemas.

\section{Conclusão}

Através dos estudos realizados, conclui-se que há uma carência de projetos relacionados na reinserção de egressos do sistema prisional brasileiro no mercado de trabalho, assim como na reintegração destes indivíduos na sociedade. Acerca das pesquisas e da organização do projeto, observou-se que o uso de um Caderno de Campo Digital facilitou o registro das atividades e o cumprimento das normas da língua portuguesa, pela agilidade e facilidade de acesso aos dados que um ambiente digital, por meio de cloud computing, proporciona.

\section{Referências}

CERVO, Amado Luiz; BERVIAN, Pedro Alcino; DA SILVA, Roberto. Metodologia científica. 6. ed. São Paulo: Prentice Hall, 2007.

DOTTI, René A. Bases e alternativas para o sistema de penas. São Paulo; Revista dos Tribunais, 1998.

GRECO, Rogério. Curso de Direito Penal: Parte Geral. $4^{\text {a }}$ ed. rev., atual e ampl. Rio de Janeiro: Impetus, v.1, 2011.

MISSE, Michel. Crime e violência no Brasil contemporâneo. Estudos de sociologia do crime e da violência urbana. Rio Janeiro: Editora Lumen Juris, 2006.

MOREIRA, Rafael. O que é Node.js? 2013. Disponível em: $<$ http://nodebr.com/o-quee-node-js/>. Acesso em: 29 de julho de 2017.

OLIVEIRA, C. Dicionário Mor da Língua Portuguesa. São Paulo: Everest Editora Pimenta \& Cia Ltda, 1972.

VASCONCELLOS, Jorge. Ministro Peluso destaca a importância do Programa Começar de Novo. Agência CNJ de Notícias, 5 set. 2011. Disponível em: $<$ http://www.cnj.jus.br/noticias/cnj/15703-ministro-peluso-destaca-importancia-doprograma-comecar-de-novo $>$. Acesso em: 29 de julho de 2017. 